\title{
Disentangling household and individual actors in explaining private electricity consumption
}

\author{
Sebastian Seebauer • Angelika Wolf
}

Received: 24 March 2015 / Accepted: 11 February 2016/Published online: 23 February 2016

(C) The Author(s) 2016. This article is published with open access at Springerlink.com

\begin{abstract}
Previous research often regard household and individual as synonymous actors, although the overall household electricity consumption is the aggregate of diverging actions by individual household members. We disentangle the impact of actor-specific predictors on household and individual electricity consumption, employing regression models to data of 204 Austrian multi-person households. Predictors add more to the explained variance of household and individual electricity consumption if they are located at the same actor level as the dependent variable. While household electricity consumption is best predicted by the household context and value/knowledge factors, individual electricity consumption depends foremost on habit and whether a person stays at home during the day. The study exemplifies that future research and interventions need to decompose actor levels to better understand and target the drivers of private electricity consumption. Methodological challenges in measuring individual and household consumption behaviour are discussed.
\end{abstract}

Keywords Conservation behaviour · Energy saving · Intra-household interaction · Explanatory model .

Regression analysis

S. Seebauer $(\bowtie) \cdot$ A. Wolf

Wegener Center for Climate and Global Change, University of Graz, Brandhofgasse 5, 8010 Graz, Austria e-mail: sebastian.seebauer@uni-graz.at

\section{Introduction}

Energy consumption in buildings - used for space heating, water heating and electrical appliancescaused about $25 \%$ of end-use greenhouse gas emissions in the EU-27 in 2009 (European Environment Agency EEA 2012). Individual electricity consumption increased by $2.5 \%$ in the EU-27 between 2005 and 2010. This detrimental trend is mainly caused by a constant increase in ownership and use of electrical appliances (e.g., TV set, computer, dishwasher), counteracting technological efficiency gains in recent years (ibid). Experts highlight that there is still considerable potential for reducing electricity consumption within the EU, if private households tackle for instance the areas of standby losses, electrical appliances and lighting (Bertoldi \& Atanasiu, 2007, 2009). Therefore, understanding the drivers of individual and household electricity consumption is crucial for elaborating strategies to reduce greenhouse gas emissions.

However, the explanation of electricity consumption represents a difficulty for current environmental research because dependent variables (e.g., overall household electricity consumption, individual appliance use) as well as predictors (e.g., household characteristics, attitudinal variables) of interest are allocated at the household and the individual level. Many studies differentiate insufficiently between these distinct actor levels and employ for instance individual environmental attitudes to explain the level of household electricity consumption. Hence, they compound household and individual characteristics to explain consumption at the 
individual or household level (Abrahamse \& Steg, 2009; Gatersleben et al. 2002; Newton \& Meyer, 2012; Poortinga et al. 2004; Whitmarsh, 2009). This approach is oversimplifying because the household's electricity consumption is the outcome of all household members' (potentially even conflicting) activities, whereas the characteristics of one respondent can no more than approximate the characteristics of all household members (Longhi, 2013; Grønhøj \& Ölander, 2007; Grønhøj \& Thøgersen, 2009; Thøgersen \& Grønhøj, 2010).

Research aim and scope

Against this background, the present study aims at disentangling the impact of household and individual level predictors to explain electricity consumption at both actor levels. In this endeavour, the same set of household and dwelling characteristics, as well as individual characteristics, is entered stepwise into explanatory models of: (a) household electricity consumption in kilowatt-hours $(\mathrm{kWh})$, derived from meter readings, and (b) self-reported individual behaviour, measured as an index of how frequently different electricity consuming actions are performed.

With this approach, we aim at demonstrating that the predictors perform better in consistent actor levels, meaning that they contribute more to explained variance in behaviour, and feature significant impacts when controlling for other predictors. Our results should advise practitioners to design interventions for reducing private electricity consumption at specific actor levels. While policies such as regulating the energy efficiency of devices or subsidizing retrofitting may be effective in targeting the entire household, strategies for fostering energy-saving practices could prove more successful when focused on open-minded or influential individuals within the household. Moreover, our review of the literature and our results underline that researchers should be more cautious about confounding household and individual actors when investigating electricity consumption.

The present study draws its predictors for explaining electricity consumption from Stern's (2000) theoretic framework to investigate environmentally significant behaviour. Here, electricity consumption is understood as environmentally significant behaviour that may be, but is not necessarily, motivated by an intention to save electricity or to benefit the environment. For all research aims, we employ regression models to survey data from 204 Austrian households.

Thematic focus on electricity consumption

This study focuses on explaining electricity consumption for lighting, household appliances, consumer electronics and similar, as this subset of overall household energy consumption serves best to contrast the household and individual actor levels. Space and water heating, which are major shares of the overall household energy consumption, typically feature indirect and background consumption which can hardly be assigned to a specific actor level. Space and water heating employ (at least in the Austrian context) a wide range of technologies and energy carriers, which makes comparison between households difficult. Our narrowed perspective on electricity consumption ensures high conceptual overlap of household and individual measures, so to underscore the discrepancies between the respective actor levels. Furthermore, since $69 \%$ of electricity consumption in Austrian households is used for powering household appliances (Statistics Statistics 2013), this constitutes a relevant field for interventions targeting everyday consumer habits.

For the purpose of this paper, we consider household electricity consumption, as shown on a meter, to emerge from the stock of electrical appliances, and how these appliances are used through the aggregated (converging, conflicting, or compensating) everyday actions of individuals (Kang \& Scott 2011; Thøgersen \& Grønhøj 2010). When investigating individual electricity consumption, we employ self-reports of individual behaviour because they can be attributed to a single household member and thus targeted by energy efficiency interventions (e.g. information campaigns teaching individuals how to conserve electricity). Note that we investigate actual electricity consuming behaviour, not savings behaviour because we do not compare the respondent's behaviour to a certain benchmark or control group. Still, we do not rule out that the actions under investigation are to some part influenced by saving intentions (see also 'Measures').

This distinction between household and individual electricity consumption, however, is not clear-cut, since an individual sometimes acts upon household needs (e.g. washing the dishes or clothes for the whole family). 
Still, the individual decides how these behaviours are undertaken (e.g. putting a lid on the pot while cooking) and thus how much electricity they consume.

\section{Theoretical background}

Operationalization of energy consumption

To identify relevant predictors of electricity consumption for our regression models, we consulted various studies in the field of household energy consumption and saving. Previous empirical research uses a wide range of perspectives on energy consumption, while the present study focuses on electricity consumption for household appliances only. Hence, the following sections draw on results on energy consumption as a proxy so that we may derive hypotheses on relevant predictors; however, this requires a clear understanding of the respective operationalizations employed.

At the household level, some authors differentiate direct (the in-house use of electricity or fuels) and indirect energy consumption, incurred by the production, transportation and disposal of consumer goods (Abrahamse \& Steg, 2009; Benders et al. 2006 Gatersleben et al., 2002; Poortinga et al., 2004). Furthermore, energy consumption refers to the absolute amount of energy used (e.g. Abrahamse \& Steg, 2009), while energy saving refers to a relative change compared to a benchmark or a control group (e.g. Benders et al., 2006; Gatersleben et al., 2002; Poortinga et al., 2004). We use this terminology to summarize previous studies in 'Predictors of electricity consumption at the household and individual' to 'Explanatory power'; the present study reported in 'Method' and 'Results' focuses on direct electricity consumption only.

At the individual level, most studies employ selfreported behaviour to examine energy consumption (e.g. Whitmarsh, 2009) or energy saving (curtailment behaviour) (e.g. Barr, Gilg \& Barr et al. 2005; Thøgersen \& Grønhøj, 2010; Thøgersen \& Ölander, 2002). Operationalizations often refer to energy consuming behaviours (e.g. turning off the light when leaving a room, avoiding stand-by electricity losses) and are adopted by the present study (for details see 'Measures').
Predictors of electricity consumption at the household and individual level

Stern (2000) proposes four main dimensions in the determining structure of environmental significant behaviour: (1) contextual factors (e.g. government regulations, interpersonal expectancies and built environment), (2) personal capabilities (e.g. socio-demographics, knowledge and skills), (3) attitudinal factors (e.g. attitudes, values and beliefs) as well as (4) habits. Stern's theoretical framework to investigate environmental significant behaviour follows a more comprehensive approach than other theories that assume proenvironmental behaviour is exclusively a result of a reasoned process, weighing costs and benefits, like the Theory of Planned Behaviour (Ajzen, 1991), or a result of (altruistic) attitudinal determinants like the Norm Activation Model (Schwartz, 1977) and the ValueBelief-Norm Theory (Stern et al. 1999). In comparison to these theories, Stern's (2000) framework is well suited to integrate egoistic and altruistic, intentional and habitual, as well as internal and external determining factors to analyse environmentally significant behaviour at the household and individual actor level.

The following sections relate previous research on drivers of private electricity consumption to Stern's (2000) four dimensions determining environmentally significant behaviour, describing their respective influence on household and individual electricity consumption:

\section{Contextual factors}

Household characteristics The most prominent (and also most obvious) driving factor of household energy consumption is household size: Larger households consume more energy (Abrahamse \& Steg, 2009; Bartiaux, 2008; Gatersleben et al., 2002; Newton \& Meyer, 2012; Poortinga et al., 2004; Statistics 2011). The role of household income is more ambiguous: Some authors find that more income leads to higher direct (Bartiaux, 2008) or overall energy consumption (Gatersleben et al., 2002; Poortinga et al., 2004). Furthermore, high-income households have a higher share of indirect energy consumption due to more purchased goods (Cohen et al. 2005). In contrast, others find no or only a weak effect on energy consumption (Abrahamse \& Steg, 2009; Newton \& Meyer, 2012) and electricity consumption (Sanquist et al., 2012; Thøgersen \& Grønhøj, 2010; 
Wiesmann et al. 2011), once other factors like household size and structure, dwelling type, floor area or appliance stock and use are controlled for.

Previous results on the effect of income and household size on individual actions of household members are inconclusive: Some authors show that higher income levels are related to a low recycling frequency, a lower level of general pro-environmental behaviour (e.g. recycling, bike usage) and a lower number of energy saving activities (Gatersleben et al., 2002; Thøgersen \& Grønhøj, 2010). Others (e.g. Sardianou, 2007) report that respondents with a higher income undertake more energy-conserving actions. Barr et al. (2005) find no relation since they identify both non-environmentalists and committed environmentalists in low-income groups. Household size has been found to have a positive effect on pro-environmental behaviour (Gatersleben et al., 2002) and a positive effect on the number of energy-conserving actions (Sardianou, 2007), implying that respondents in larger households behave more proenvironmentally. However, Barr et al. (2005) conclude that committed and mainstream environmentalists tend to have smaller household sizes than occasional or nonenvironmentalists.

Dwelling characteristics Among different dwelling characteristics, higher electricity consumption at the household level is predominantly related to larger home sizes (floor area) and the dwelling type of a detached house in comparison to apartment buildings (Statistics 2011; Thøgersen \& Grønhøj, 2010; Wiesmann et al., 2011; Yohanis et al. 2008). At the individual level, Sardianou (2007) identifies a positive effect of ownership and dwelling type (detached house), but no effect of floor area on the number of reported energy-conserving actions.

Summing up, household and dwelling characteristics are expected to be potent drivers of electricity consumption at the household level, but not at the individual level. This is supported by Gatersleben et al. (2002) who show that the influence of household size and income on individual behaviour is low $(\beta=.01-.12)$ compared to their effects on household energy consumption $(\beta=.22-.53)$.

Electrical appliances As additional contextual factor, we also include the stock of electrical appliances in the household because all household members may access appliances and use them for their joint benefit (e.g. doing the family laundry). Previous studies point out that the direct effect of income on household electricity consumption decreases or becomes insignificant when the number of electric appliances is controlled for (e.g. Sanquist et al., 2012; Thøgersen \& Grønhøj, 2010; Wiesmann et al., 2011).

\section{Personal capabilities}

Socio-demographic characteristics At the household level, the influence of individual socio-demographics on electricity consumption can be considered as negligible: Gender does not feature a significant effect (Abrahamse \& Steg, 2009; Newton \& Meyer, 2012). The results regarding age are contradictory, as households with older respondents are found to consume more (Newton \& Meyer, 2012), less (Gatersleben et al., 2002; Statistics 2011) or the same amount of energy as younger respondents (Abrahamse \& Steg, 2009; Poortinga et al., 2004). The same holds true for education, either displaying a non-significant effect (Gatersleben et al., 2002; Statistics 2011) or indicating that a higher level of education is related to lower energy consumption (Poortinga et al., 2004). Finally, employment is found to have an impact to the extent that unemployment implies more electricity consumption (Statistics 2011).

Findings regarding socio-demographics are also inconsistent at the individual level: Age is considered as influential for carrying out energy-saving tasks to the extent that older respondents either act more (Barr et al., 2005; Gatersleben et al., 2002; Whitmarsh, 2009) or less pro-environmental (Sardianou, 2007). According to Sardianou (2007) gender does not affect individual behaviour. However, Barr et al. (2005) find that women are more committed energy savers than males. As division in household chores varies by gender, male and female partners engage differently in energy saving (Carlsson-Kanyama \& Lindén, 2007). According to Gatersleben et al. (2002), higher education positively influences general pro-environmental behaviour. However, Barr et al. (2005) and Sardianou (2007) cannot replicate an effect of education on individual behaviour to conserve energy.

Overall, the effects of individual socio-demographics on household electricity consumption are expected to be marginal compared to household and dwelling characteristics because they are smaller in magnitude throughout (Abrahamse \& Steg, 2009; Gatersleben et al., 2002; 
Poortinga et al., 2004). We also assume that, at the individual level, socio-demographics have a rather small impact on individual electricity saving.

Knowledge how to save energy Neither at the household level nor at the individual level, Bartiaux (2008) and Whitmarsh (2009) find any effect of individual climate change knowledge on electricity consumption or possession of energy efficient appliances. Better knowledge is even related to a higher number of large appliances in the household and to a more frequent use of certain home appliances (such as washing machine and dishwasher; Bartiaux, 2008).

However, knowledge on ecological systems, as measured in these two studies, rarely translates into practice. Frick, Kaiser and Wilson (2004), for instance, show that 'system knowledge' has no direct effect on environmental conservation behaviour; instead, its effect is mediated via 'action-related' and 'effectiveness knowledge', which in turn influence individual electricity consumption to a moderate degree. Regarding energy saving intentions instead of actual behaviour, the subjective assessment of how well informed respondents feel about the issue of climate change is relevant (Sardianou, 2007).

Perceived behavioural control to save energy Perceived behavioural control (PBC) refers to how much respondents feel capable of conserving energy in their household. At the household level, Abrahamse and Steg (2009) do not find a significant influence of PBC on energy use.

At the individual level, Barr et al. (2005) conclude that committed energy savers have a higher level of PBC regarding environmental actions. Thøgersen and Grønhøj (2010) identify perceived impediments and facilitators as significant determinants of energy saving. Although findings regarding electricity consumption are rare, the influence of $\mathrm{PBC}$ on individual behaviour via intention was successfully demonstrated within the framework of the theory of planned behaviour (Ajzen, 1991). This applies to various circumstances, such as travel mode choice or environmental conservation activities (e.g. Bamberg et al. 2003; Kaiser et al. 2005; for a meta-analysis see Armitage \& Conner, 2001).

As previous studies indicate that PBC is not relevant at the household level, but relevant at the individual level, we assume that its effect is larger on individual behaviour related to electricity consumption.
Attitudinal factors

Attitudes towards energy-saving measures, personal norms, as well as environmental concerns are considered non-influential on household energy consumption (Abrahamse \& Steg, 2009; Poortinga et al., 2004). Still, Gatersleben et al. (2002) find a significant effect of environmental awareness and beliefs on household energy consumption. Regarding individual energy saving, various studies detect effects of perceived responsibility for environmental problems (Sardianou, 2007), environmental concern (Poortinga et al., 2004) as well as environmental awareness and values (Barr et al., 2005; Gatersleben et al., 2002). In contrast, Whitmarsh (2009) does not find a significant impact of environmental values and perceived moral obligation on individual energy use.

From the range of attitudinal factors, the present study focuses on environmental values based on the widely applied concept of the New Environmental Paradigm (NEP; Dunlap, 2008; Amburgey \& Thoman, 2012). In the area of electricity consumption, Clark, Kotchen and Moore (2003), for instance, found a significant influence of the NEP on the decision to voluntarily participate in a green electricity program.

The previous evidence suggests that environmental values are not influential at the household level, even though their impact on individual behaviour is widely acknowledged.

\section{Habits}

Habitual behaviour is characterized by a high degree of automaticity that reduces or even bypasses deliberative choices because certain responses are spontaneously triggered by a specific cue in the environment (Verplanken, 2006). The impact of habit on individual behaviour was successfully demonstrated in various behavioural areas like travel mode choice (Aarts et al. 1998), recycling (Knussen \& Yule, 2008) or eating (Verplanken, 2006). In a laboratory experiment of turning off the light upon leaving a room, De Vries, Aarts and Midden (2011) found that when distracted, a person's habits are automatically triggered by the situation. Thus, habits are difficult to control by intentions, impeding the ability to learn new behaviours which consume less electricity. The few findings on the role of habits suggest that they might have an impact on 
individual electricity consumption; still, their effect has not yet been established empirically.

\section{Explanatory power}

The various studies cited above achieve explained variances in household energy consumption of 13-54\%, depending on the range of included predictors. Generally, explained variance is higher if appliance use and individual energy-saving behaviour are included to predict household energy use in $\mathrm{kWh}$. Household size is a consistent predictor, whereas attitudinal variables add little explained variance (e.g. $R^{2}=3 \%$ of attitude in Abrahamse \& Steg, 2009). At the individual level, explained variances range from 13 to $26 \%$. Attitudinal variables exhibit a stronger effect at the actor level of the individual. Summing up, as far as general conclusions can be drawn from the multitude of investigated determinants and behaviours, all four dimensions (contextual factors, personal capabilities, attitudinal factors and habits) exhibit stronger explanatory power if both, the predictor and the predicted behaviour, are allocated at the same actor level of the household or the individual.

\section{Method}

\section{Participants}

The data for the present research are drawn from the baseline interviews with 204 households who participated voluntarily in a smart metering pilot project in the cities of Graz and Klagenfurt, and the rural district Hartberg, all located in southern Austria. These regions represent typical urbanized and rural regions in Austria and may be generalized to other industrialized countries with similar private electricity demand. All data employed here were collected prior to the pilot trial, i.e. before the participants could access information from their smart meters. The participants were recruited from the customers of three electric utility companies.

The survey was conducted during June-September 2011 in two steps: Participants received a written, standardized questionnaire. Within each household, one representative person (the adult who spends the most time at home) was instructed to fill in the questionnaire. However, contrary to prevalent gender roles for staying at home in Austria, in most cases, men completed the questionnaire, presumably because they felt responsible for the participation in the smart metering project which required some technical installations in the participant's homes. After returning the questionnaire, an energy consultant visited the households and interviewed the questionnaire respondent face-to-face to complete missing data and to assess knowledge how to save energy via quiz questions. Thus, our data contains responses of one individual per participating household.

As we aim to compare actor levels in private electricity consumption, the sample includes only households wherein several persons live together. In singleperson households, the household and individual level converge; thus, including single households would diminish the informative value of our results. The group size of single households $(n=21)$ was too small for a comparative analysis.

Compared to the population in the regions under investigation, the sample is biased towards men $(73 \%)$ and higher educated persons (46\%). In correspondence with higher education, the sample also has a tendency towards higher incomes, bigger floor areas and an overproportional share of detached houses (see Appendix Table 5). A similar bias is also present in other studies. Abrahamse and Steg (2009), for instance, report a quota of $64 \%$ men, an overrepresentation of higher incomes as well as $73 \%$ homeowners. In our case, the sample bias might be connected to the recruitment for the smart metering intervention that favoured owned houses for feasibility of technical installations.

\section{Measures}

Annual household electricity consumption Respondents reported their annual electricity consumption in $\mathrm{kWh}$ for the years 2008, 2009 and 2010 from their electricity bills. The responses were validated with customer information from the utility companies. To compensate for yearly fluctuations, the values of the 3 years were averaged for each household.

To improve conceptual alignment between the measures for household and individual electricity consumption, we excluded electricity used for space and water heating (see 'Thematic focus on electricity consumption'). In the majority of the sample, a dedicated meter recorded electricity exclusively used for household appliances. For 68 households, total electricity consumption was disaggregated following guidelines of local energy consultants, therein considering the dwelling's 
energy efficiency rating and household size (Statistics 2011). As the disaggregation procedure yields only estimates of electricity use for household appliances, it introduces some inaccuracy into these households' consumption data; however, the alternative of retaining electricity for heating and hot water would have confounded behavioural areas and would have led to ambiguous interpretation of results. Therefore, the data analysed here are restricted to electricity consumption for lighting, household appliances, consumer electronics, as well as large devices like a sauna or a swimming pool circulation pump, if any.

Individual electricity consumption Individual behaviour was measured by a mean index comprised of four items, indicating how often respondents undertook the following activities during the past year: putting a lid on the pot when cooking on the electric kitchen stove, ${ }^{1}$ using the standby mode of frequently used electronic devices like PCs or TVs between usages (reverse direction), using the washing machine even when half-loaded (reverse direction) and turning off the light when leaving a room for half an hour. Individual electricity consumption was measured with only four activities to reduce overall respondent burden. Note that these activities are typically featured in energy-saving guides and previous studies, although these specific behaviours might have little impact on total electricity consumption. All items are translated from German. Responses were given on a five-step rating scale $(1=$ always, $5=$ never $)$. Like the measure on the household level, these items excluded electricity used for space and water heating. Similar to previous studies (e.g. Gatersleben et al., 2002; Thøgersen \& Grønhøj, 2010; Thøgersen \& Ölander, 2002; Whitmarsh, 2009), we consider individual electricity consumption a formative concept and aggregated all items to a mean index despite inconsistency across these activities (see correlations in Table 1). The higher the index, the higher the level of electricity consumption. This conceptualization assumes that consumers choose from a range of behavioural options based on their abilities, opportunities and motivation. For a critical discussion of this mean index, see 'Limitations in measurements'.

Inferring from their phrasing, the individual behaviour items capture electricity consuming actions, not

\footnotetext{
${ }^{1}$ Households in our sample do not use natural gas for cooking; thus, this item refers to electric stoves only.
}

savings intentions. The reverse direction of half of the items underlines this aspect as a person would hardly intend, e.g. to leave devices on standby mode for the sake of the environment. Measuring saving behaviour would require a relative comparison to a previous situation or a reference group. Still, we cannot preclude that an underlying motivation for electricity conservation may have coloured the responses.

As the index applied here also includes behaviours undertaken for the mutual benefit of other household members (cooking, using the washing machine), it might be argued that the index does not capture exclusively individual behaviour. However, the items do not ask for the frequency but the quality of behaviours. It is for instance still the cook's decision to put the lid on the pot or not. In a similar vein, possibly some respondents referred to consumption practices prevalent among fellow household members. Still, they were clearly instructed to report their very own behaviour.

Household appliance stock The number of household appliances subsumes several electrical appliances (fridge, freezer, stove, water boiler, dishwasher, microwave, washing machine, tumble dryer, vacuum cleaner and coffee machine) to a sum index. Likewise, the number of consumer electronics includes the following appliances: TV, DVD-player/-recorder, radio/hi-fi system, PC/notebook/ game console. The number of so-called 'luxury' appliances sums up several appliances with particularly high electricity use not common in ordinary Austrian households (sauna, infrared cabin, swimming pool equipment, aquarium/terrarium, air condition, water bed). Strictly speaking, summing up assumes that all appliances contribute equally to the respective index. However, assessing exact power input and usage of each device would have exceeded respondent burden. Thus, the appliance indices should be interpreted as formative indicators of a household's lifestyle.

Contextual factors Respondents indicated the household size in terms of the number of household members and gave the floor area of their apartment or house in square meters. They further estimated their net monthly household income in euros on a four-step scale, corresponding to the quartiles of the Austrian income distribution that was afterwards converted into a metric scale using the respective category midpoints (similar to Fujii \& Kitamura, 2003). The equivalent household income corrects the household income by the household size, weighing adults higher than children (Statistics 2010). 
Table 1 Correlations between individual and household electricity consumption

\begin{tabular}{lllll}
\hline Constructs/items & $\mathrm{kWh}$ & Index & Item 1 & Item 2 \\
\hline Household electricity consumption (kWh) & 1 & & & \\
Individual electricity consumption (index) & .08 & 1 & & \\
Lid on the pot (item 1) & -.07 & $.38^{* *}$ & 1 & 1 \\
Stand by (item 2) & .12 & $.72^{* *}$ & .02 & .05 \\
Washing machine (item 3) & -.03 & $.42^{* *}$ & -.08 & -.06 \\
Turning off light (item 4) & .09 & $.41^{* *}$ & .12 & -.09 \\
\hline
\end{tabular}

${ }^{a}$ For item wording, see 'Measures'

Pearson correlations: $* * p<.05$

The type of dwelling was assessed dichotomously, where 0 indicates an apartment in a building with three or more units, and 1 a detached house for one or two families.

Personal capabilities Age was assessed continuously in years. Gender (female $=0$, male $=1$ ), education (primary or secondary education $=0$, higher education including school leaving exam or university-level education $=1$ ) as well as employment (maternal leave, housekeeping, retirement, unemployment (at home) $=0$; full/part-time employment, military service, education (not at home)=1) were measured dichotomously. To assess knowledge, respondents were asked quiz questions about the best options for energy saving, each quiz question featuring four multiple choice options with one correct answer (see Appendix Table 4). The quiz questions were derived from Frick (2003) and Piskernik (2007) and built upon the expertise and educational materials of energy consultants. The six quiz questions feature various item difficulties with a share of correct answers ranging from 46 to $96 \%$, thus enabling good differentiation between well- and less-informed respondents. Most cases showed monotonous response patterns. Therefore, we may assume that the knowledge measure is unbiased by randomized guessing and not confounded with environmental attitudes. Note that knowledge was assessed in face-to-face-interviews, thereby prohibiting quick information searches on the Internet or consultation with other household members. The quiz questions were aggregated formatively to a sum score, correcting for missing values by referring the number of correctly answered questions to the total of completed questions. ${ }^{2}$ A higher score indicates better knowledge. Perceived behavioural control (PBC) was measured with two items: If I wanted to save energy, I could easily reduce my electricity consumption for electronic appliances, cooking and lighting (PBC1). Even though my energy consumption is predetermined by the conditions within the household (e.g. electrical appliances, insulation), I can lower it with my daily actions (PBC2). The items were assessed on a five-step rating scale, where 1 indicates the most favourable response. The wording was held close to common operationalizations of $\mathrm{PBC}$ in the previous literature (e.g. Abrahamse \& Steg, 2009; Bamberg et al., 2003; Kaiser et al., 2005). PBC items were aggregated to a mean index, with Cronbach's $\alpha=.53$. While this does not meet common standards of $\alpha>.70$, short scales consisting of few items are generally impaired by weaker measurement reliability (Bortz \& Döring, 2006). According to the response scale, higher rankings indicate a lower level of PBC.

Attitudinal variables Environmental values were assessed with three items of the New Environmental Paradigm (NEP) scale, developed by Dunlap and Van Liere (Dunlap, 2008; Amburgey \& Thoman, 2012; Clark et al., 2003). We used the English-German trans-

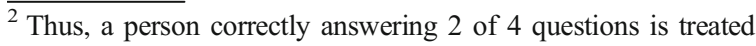
equally as a person correctly answering 3 of 6 questions, both receiving a knowledge score of 3 . Missing answers are not coded as incorrect because response refusal might be an attempt to hide ignorance, but could also imply irritation, lack of interest, etc.
} 
lation from the European Values Study (2008): The balance of nature is strong enough to cope with the impacts of modern industrial nations (NEP1). Humans were meant to rule over the rest of nature (NEP2). Human ingenuity will insure that we do not make the earth unlivable (NEP3). The items were assessed on a five-step rating scale, with 1 indicating the most favourable response. The mean index yields Cronbach's $\alpha=.59$. As all three items reflect negative statements, higher rankings indicate stronger proenvironmental values.

Habits The measurement of habits has proven to be difficult when target behaviours involve more than a single action (Knussen \& Yule 2008). Therefore, the automaticity of electricity consumption is measured based on the lack of awareness respondents have regarding the use of electrical appliances, cooking and lighting (see also De Vries et al. 2011; Verplanken \& Orbell, 2003 for measures of subjective habit strength). Respondents indicated their agreement to the following statements on a five-step rating scale (1 indicates the most favourable response): In my daily actions, I use energy for electrical appliances, cooking and lighting without conscious thinking (Habit 1). In my everyday life, I do not give much thought to my energy consumption for electrical appliances, cooking and lighting (Habit 2). Aggregated to a mean index, habit features Cronbach's $\alpha=.56$. Higher rankings refer to weak habits. Table 5 in the Appendix gives descriptive statistics for all items in the statistical analyses.

\section{Data analysis procedure}

Household and individual electricity consumption is regressed separately on the same set of household and individual characteristics. ${ }^{3}$ Stern's (2000) dimensions of environmental significant behaviour, as outlined in 'Contextual factors', 'Personal capabilities', 'Attitudinal factors' and 'Habits' are entered stepwise as blocks of predictors into the regression. We start with household

\footnotetext{
${ }^{3}$ As an alternative to regression models, structural equation modelling could employ PBC, environmental values, and habit as latent factors, therein accounting better for item measurement error than the indices applied here, and allowing for interrelations between predictors. However, the sample size is too small for so complex a SEM model. Still, we also conducted a SEM analysis and achieved similar results.
}

characteristics when explaining household electricity consumption and then compare whether individual characteristics show a statistically significant influence when controlling for the impact of household predictors. In turn, starting with individual characteristics to explain consumption on the individual actor level, we check for additional explanatory power unique to household characteristics. The adjusted $R^{2}$ shows the stepwise increase in explained variance while correcting for the increasing overall number of predictors in each step.

As the household/dwelling characteristics and sociodemographics reflect various aspects of a household's living conditions and social milieu, they are naturally intercorrelated (e.g. type of dwelling and floor area, $r=.54$; floor area and household size, $r=.33$; age and employment, $r=-.59$ ), being at risk of multicollinearity. However, regression diagnostics are uncritical, with variance inflation factors smaller than 2 throughout.

We apply multiple imputations to account for missing data (Manly \& Wells, 2014). Multiple imputation estimates missing values from the probability distribution of possible values as observed in the available data, thereby leveraging the known, albeit partial information for full effect. Imputing multiple samples retains the uncertainties caused by missing data, as the randomness during the estimation of missing values yields slightly diverging samples. Multiple imputation is considered superior to listwise deletion, where the partial information from deleted cases is lost entirely for analysis, which may bias the results, and also outperforms other imputation methods (Manly \& Wells, 2014).

Across all cases and variables, $12.5 \%$ of data points are missing due to respondent fatigue. Item-specific nonresponse is shown in Table 5. Employing listwise deletion would more than halve the sample size to 93 valid cases featuring complete information in all variables for analysis. Instead, we construct 50 imputed samples, estimating missing values from all variables used in the analysis, plus additional items on selfreported energy saving behaviour as auxiliary variables.

Multiple imputation is used in all regression analyses. As recommended by Manly \& Wells (2014), Tables 2 and 3 report median coefficients across all 50 imputed samples, wherever pooled coefficients are not available. For reference, Tables 6 and 7 in the Appendix give the regression coefficients with listwise deletion, as well as the minimum and maximum coefficients obtained across all imputed samples. The data imputation and all statistical analyses were carried out in SPSS 21. 
Table 2 Effects of contextual factors, personal characteristics, attitudinal factors and habits on household electricity consumption

\begin{tabular}{|c|c|c|c|c|}
\hline & $1 \mathrm{a}$ & $2 \mathrm{a}$ & $3 a$ & $4 a$ \\
\hline Household size & $.19 * *$ & $.20 * *$ & $.20 * *$ & $.21 * *$ \\
\hline Equivalent household income & -.03 & -.09 & -.09 & -.08 \\
\hline Type of dwelling & $.23 * *$ & $.24 * *$ & $.25^{* *}$ & $.25 * *$ \\
\hline Floor area & $.22 * *$ & $.21 * *$ & $.22 * *$ & $.22 * *$ \\
\hline Number of household appliances & .12 & $.20 *$ & $.18^{*}$ & .17 \\
\hline Number of consumer electronics & .07 & .05 & .05 & .04 \\
\hline Number of luxury appliances & $.18^{* *}$ & $.14 * *$ & $.14 * *$ & $.15^{* *}$ \\
\hline Gender & & .04 & .05 & .06 \\
\hline Age & & .06 & .07 & .06 \\
\hline Education & & $.14 * *$ & $.14 * *$ & $.14 * *$ \\
\hline Employment & & -.05 & -.05 & -.05 \\
\hline $\mathrm{PBC}$ & & .00 & .00 & .02 \\
\hline Knowledge & & $.18^{* *}$ & $.17 * *$ & $.17 * *$ \\
\hline Environmental values & & & $-.14 * *$ & $-.14 * *$ \\
\hline Habit & & & & -.09 \\
\hline$R^{2}$ adjusted [\%] & 39.2 & 43.3 & 45.2 & 45.8 \\
\hline$R^{2}$ change $[\%]$ & - & 4.1 & 1.9 & 0.6 \\
\hline $\mathrm{F}$ & $19.7 * *$ & $12.9 * *$ & $13.0 * *$ & $12.4 * *$ \\
\hline $\mathrm{df}$ & 7 / 196 & $13 / 190$ & $14 / 189$ & $15 / 188$ \\
\hline
\end{tabular}

$\mathrm{a}=$ household electricity consumption; standardized regression coefficients (median coefficients from 50 imputed samples)

$* * p<.05 ; * p<.1$

\section{Results}

Correspondence between individual and household electricity consumption

The initial analysis turns to the question as to what extent electricity consumption at the household and individual level correspond to each other. We find strong divergence between the behavioural measures, underlining that not just predictors, but also the explained behaviour varies between actor levels.

Table 1 displays that items 1 to 4 on individual electricity consumption are marginally correlated among each other $(r=.02$ to $r=.12)$. These findings point to inconsistent behaviour of individuals related to electricity consumption. Following previous studies which found the same results (e.g. Thøgersen \& Grønhøj, 2010; Thøgersen \& Ölander, 2002), we thus aggregated a formative mean index (see 'Measures'). Hence, the index of individual electricity consumption reflects to what extent respondents undertake any of the four types of behaviours.

In line with previous results (e.g. Gatersleben et al., 2002), Table 1 shows that the index of individual electricity consumption is not correlated to household electricity consumption $(r=.08)$. In contrast, Thøgersen and Grønhøj (2010) found a significant impact of individual energy saving on household electricity consumption $(\beta=-.26)$. However, Thøgersen and Grønhøj also included purchasing behaviours (e.g. buying energy saving light bulbs) and control behaviours (e.g. controlling the temperature in fridges and freezers) in their measure of individual behaviour.

High divergence between individual and household electricity consumption may be attributed to three reasons: First, as stated above, it seems that individuals hardly show a general, consistent tendency in electricity consuming behaviours, which could be the statistical counterpart to the total electricity a household consumes. 
Table 3 Effects of contextual factors, personal characteristics, attitudinal factors and habits on individual electricity consumption

\begin{tabular}{|c|c|c|c|c|}
\hline & $1 b$ & $2 b$ & $3 b$ & $4 \mathrm{~b}$ \\
\hline Household size & & & & .01 \\
\hline Equivalent household income & & & & .09 \\
\hline Type of dwelling & & & & .02 \\
\hline Floor area & & & & -.07 \\
\hline Number of household appliances & & & & .02 \\
\hline Number of consumer electronics & & & & .00 \\
\hline Number of luxury appliances & & & & -.11 \\
\hline Gender & & & -.04 & -.05 \\
\hline Age & & & -.07 & -.07 \\
\hline Education & & & .06 & .05 \\
\hline Employment & & & $-.25 * *$ & -.27 \\
\hline PBC & & & -.09 & -.09 \\
\hline Knowledge & & & .03 & .01 \\
\hline Environmental values & & -.08 & -.08 & -.08 \\
\hline Habit & $-.20 * *$ & $-.19 * *$ & $-.18 * *$ & -.18 \\
\hline$R^{2}$ adjusted [\%] & 3.5 & 3.9 & 7.5 & 6.8 \\
\hline$R^{2}$ change $[\%]$ & - & 0.4 & 3.6 & -0.7 \\
\hline $\mathrm{F}$ & $8.4 * *$ & $5.1 * *$ & $3.0 * *$ & $2.0 * *$ \\
\hline df & $1 / 202$ & $2 / 201$ & $8 / 195$ & $15 / 188$ \\
\hline
\end{tabular}

$\mathrm{b}=$ individual electricity consumption; standardized regression coefficients (median coefficients from 50 imputed samples)

$* * p<.05 ; * p<.1$

Second, according to Thøgersen and Grønhøj (2010), an environmentally significant measure of individual electricity consumption should comprise not only routine activities, but also control and purchasing activities. However, even in 'avoidable' daily routines like standby consumption lies considerable saving potential (Bertoldi $\&$ Atanasiu, 2007, 2009). Third, the contribution of the individual to the overall household electricity consumption is small and may be attenuated or contradicted by the actions of other household members.

Next, we show that not just individual and household behaviours are divergent, but also the drivers underlying these behaviours.

Drivers of individual and household electricity consumption

We compare the drivers of electricity consumption at both actor levels, employing Stern's (2000) four dimensions of predictors. Stepwise, (1) contextual factors (household and dwelling characteristics, as well as appliance stock), (2) personal capabilities (socio-demographics, knowledge, perceived behavioural control), (3) attitudinal factors (environmental values) and (4) habits are entered into explanatory models of: (a) household and (b) individual electricity consumption to compare the respective explanatory power at both actor levels. Tables 2 and 3 display the standardized regression coefficients as well as explained variance in consumption for each model (1a to $4 \mathrm{~b}$ ).

All models displayed in Tables 2 and 3 exhibit significant F-values, meaning that in all models the set of included predictors does indeed explain more than zero variance in electricity consumption. Explained variance $\left(R^{2}\right)$ in individual consumption is rather low throughout; however, our interest lies in model comparison rather than in generalizing from single models (see also the discussion 'Limitations in explanatory power'). 
The best performing models ( $4 a, 3 b)$ explain $46 \%$ of variance in electricity consumption at the household level and $8 \%$ at the individual level, lying in the range of previous findings (see section 'Explanatory power'). Household and dwelling characteristics provide a large part of explained variance in household electricity consumption $\left(R^{2}=39 \%\right.$, model 1a), but hardly contribute to self-reported individual behaviour (model $4 \mathrm{~b}$, with a slight decrease in $R^{2}$ ). Relative to the initial $R^{2}$, personal capabilities contribute weakly to explaining household consumption $(+4 \%$, model $2 \mathrm{a})$ and considerably to the explained variance at the individual level $(+4 \%$ in model 3b, nearly doubling the previous model's $R^{2}$ ). Environmental values increase the explained variance to a small degree not only at the individual $(+0.4 \%$, model $2 \mathrm{~b}$ ), but also at the household level $(+2 \%$, model $3 a)$. Finally, habits have little unique explanatory power in household electricity consumption $(+1 \%$, model $4 a)$, but play a considerable role in individual electricity consumption ( $4 \%$, model $1 \mathrm{~b}$ ). Thus, these findings support the primary goal of this study, as they indicate that predictors add more to the explained variance if the dependent variable is located at the same actor level.

Next, the unique impacts of predictors are compared between the four consecutive model steps: Regarding contextual factors of household electricity consumption, all household and dwelling characteristics, apart from household income, feature significant impacts, consistent with the previous literature that household size and dwelling characteristics are important drivers of household electricity consumption. The stock of luxury appliances, i.e. less common devices with high power input, drives overall electricity consumption, whereas the stock of household appliances, i.e. commonplace and everyday devices, only shows marginally significant influence in some models. Among the personal capabilities, the level of education and energy-saving knowledge emerge as strong predictors, to the extent that higher educated and well-informed respondents live in households which consume more electricity. This might indicate a more energy-intensive lifestyle of technophile respondents possessing multiple electronic devices, independent of their income. The counter-intuitive effect of knowledge might reflect a higher problem awareness based on past experiences with the own problematic electricity consumption, pushing the development of cognitive skills how to save energy. However, according to Bartiaux (2008), higher levels of knowledge are not necessarily translated into everyday practices of electricity saving. Alternatively, as the knowledge quiz questions address a wider and presumably more environmentally significant range of behaviours than the assessed individual consumption behaviours, the respondents may consider the latter not worth the effort. Strong pro-environmental values leverage lower household electricity consumption. Presumably, the values stated by the respondent approximate fairly well the values of his or her fellow household members; this is supported by Schweighart, Seebauer \& Fleiß (2014) who report that environmental values within cohabiting couples correlate with $r=.50$. Households holding proenvironmental values might act more in concert regarding everyday electricity consumption. Additionally, they might make more investments in efficient appliances or lighting to keep their overall level of consumption low.

In contrast, neither household and dwelling characteristics nor appliance stock has a significant impact in our models of individual electricity consumption, pointing to the independence of individual consumption behaviour from the household level. At the individual level, employment is the only significant predictor among the personal capabilities: Persons staying at home more often undertake electricity intensive behaviours than employed persons. This result might be explained by their daily activity at home and thus a certain level of automaticity in their everyday routines, interfering with efforts at reducing electricity consumption. Pro-environmental values are not translated in everyday individual activities. On the contrary, environmental values seem to rather influence long-term investment choices and appliance purchases at the level of the entire household. Finally, habit features a significant negative coefficient. Hence, respondents who express a high degree of automaticity more often conduct tasks associated with higher electricity consumption.

Summing up our regression results, household electricity consumption is mainly driven by contextual factors (household size, type of dwelling and floor area), but higher consumption is also influenced by higher education and knowledge levels as well as by low environmental values. In the latter predictors, the individual responses seem to be fairly good proxies of the household's capabilities, rendering the distinction between actor levels less clear-cut for those variables. In comparison, only habits and employment status could be identified as significant predictors of individual behaviours. Household income, the stock of some 
electrical appliances, gender, age and perceived behavioural control did not emerge as relevant drivers in any of the models. Overall, these findings are in accordance with previous studies on household and individual electricity consumption (see 'Predictors of electricity consumption at the household and individual level').

\section{Discussion and limitations}

The study aimed at disentangling the effect of household and individual level predictors on electricity consumption, at both actor levels. The general expectation, that individual behaviour is more strongly related to individual predictors, whereas household electricity consumption is primarily related to household and dwelling variables, is met. Regression models show that household characteristics do not contribute to the explained variance in individual behaviour; in turn, individual characteristics only explain a small part of the variance in household electricity consumption $\left(R^{2}=6.6 \%\right.$ out of $45.8 \%)$. The overall explained variance is within the range of previous findings. The results underline the need for a clear conceptual distinction of actor levels when researching private electricity consumption. In this respect, our findings expand on previous studies that jointly use, and thus confound, individual and household level predictors to explain either household or individual electricity consumption.

\section{Limitations in measurements}

Some limitations regarding the measurement of individual and household behaviour need to be considered within the present study: The self-reports on individual electricity consumption have not been validated whether they correctly reflect the respondent's actions in real life. The low correlation $(r=.08)$ between individual and household consumption as well as the weak explained variance in individual consumption suggest that relevant individual behaviours are missing in our index of individual electricity consumption. Covering more than four behaviours might improve measurement reliability and thereby increase concordance between the household and individual level. However, previous research questions whether a general tendency towards consuming more or less electricity across diverse behavioural areas even exists at the individual level (Gatersleben et al.,
2002; Thøgersen \& Grønhøj, 2010; Thøgersen \& Ölander, 2002; Whitmarsh, 2009). A broader concept, also including purchase and control behaviours of electric appliances, could achieve higher congruence with household electricity consumption but would introduce actor level ambiguity because of less clear assignment to a single individual's actions. Similarly, extending the scope of energy-consuming actions to water and room heating would lead to ambiguity between behavioural areas and thus less interpretable results (see 'Thematic focus on electricity consumption'). The issue how to deal with diverse, inconsistent, more or less environmentally significant behaviours which in their entirety constitute electricity consumption has yet to be solved in future research.

Household electricity consumption has limitations as an indicator, too. It is a highly aggregated indicator of the multitude of activities in a modern household that demand electricity (cooking, listening to music, personal hygiene, cleaning, playing, etc.). Presumably, many people do not associate all of these everyday activities with the total electricity demand they find on their electricity bill. However, household electricity consumption is the target variable of environmental policies for demand-side reductions, so it is crucial despite its ambiguity.

Taking the limitations in the measures of household and individual electricity consumption together, low conceptual overlap between the aggregated, total household meter reading and the small set of four narrow individual activities could provide an alternative interpretation for our results. If the behavioural measures represent different things, it would seem naturally that they do not share the same predictors. However, these measures are widely applied in research and practice, collecting self-reports from all household members demands considerable effort and a practical way to meter individual consumption in $\mathrm{kWh}$ over a range of different appliances has yet to be developed. At the least, our results may provide an important caveat to researchers investigating private electricity consumption.

\section{Limitations in explanatory power}

Explained variance in our models on electricity consumption might suffer from omitted variable bias. Additional predictors to increase $R^{2}$ are easily conceivable. However, this study's approach relies on stepwise model comparison of predictors assigned to specific 
actor levels, not on building a comprehensive explanatory model. Future studies could expand on dimensions which blur the distinction between individual and household actor levels such as interactions between household members or background consumption.

Household members interact by coordinating their schedules how they organize everyday activities (Kang $\&$ Scott, 2011) and by agreeing on similar values through reciprocal socialization (Hurrelmann et al., 2008). The various persons in a household may follow their own needs and agendas when it comes to enacting or refraining from electricity-consuming activities. Simply dividing the total $\mathrm{kWh}$ a household consumes by the number of persons in the household (e.g. Statistics 2011) disregards that children versus adults or employed versus housekeeping persons contribute differently to the overall consumption of the household. For practical reasons, most studies in this field interview just a single respondent as a proxy for the household. Only a few studies interview more than one household member (e.g. Longhi, 2013; Schweighart et al. 2014; Thøgersen \& Grønhøj, 2010). These aspects make it difficult for survey studies, such as this, to account for the complex dynamics and interactions within a household. Future research could collect data from all (or several) members of the household and integrate this data in a multi-level modelling approach.

Another avenue to improve explanatory power could be to disentangle direct and background electricity consumption. While direct consumption stems from the everyday actions of individuals, background consumption refers to the base demand for electricity emerging from the number, size and efficiency of electrical devices or a household's standard of living. In terms of environmental significance, background consumption may often have the far stronger impact. Although seemingly allocated at the household level, it also involves individual actors: Some individual behaviours influence background consumption (like use of standby mode assessed here or holding the refrigerator door open as shortly as possible). Appliance stock and usage stands as an intermediary between household and individual actors, as the household purchases the appliance but the individual uses it. Inefficient appliances may lead to a lock-in situation wherein the household members find little leeway for influencing their overall consumption through changing everyday behaviours. Still, our regression analysis shows unique effects of other predictors when controlling for the impact of appliance stock. This underlines that household electricity consumption is not entirely predetermined by long-term investments choices in appliances and lifestyle. Future research could employ structural equation modelling in order to distinguish between direct and background consumption and to identify respective impacts of the applied predictors on these two dimensions. However, such complex models require large samples.

Limitations in data

The findings reported here are based on correlational data that do not allow for verifying the causal direction of the proposed paths. Nevertheless, the paths in the models are well established in the literature and in some cases quite obvious (e.g. household size influences electricity consumption). Replication in a longitudinal or experimental study would be desirable, especially to elaborate on the unclear interrelation between household members.

Finally, due to small sample sizes, we could not compare single-person households to multi-person households. Still, this comparison would be interesting for future studies since single-person households provide a reference case with identical household and individual electricity consumption.

\section{Conclusions and policy implications}

Regarding the relevant drivers based on Stern's (2000) theoretical framework, our study identifies several contextual factors (type of dwelling, floor area and household size) that contribute highly to the explanation of household electricity consumption. Among the personal capabilities, better knowledge on energy saving is found to lead to higher household electricity consumption. This counter-intuitive effect challenges the effectiveness of common information campaigns and calls for better alignment which behaviours are taught and enacted. Regarding attitudinal factors, strong environmental values imply less consumption. Possibly, household members share similar environmental values and agree to act concordantly or invest in more energy-efficient appliances and lighting. Hence, interventions might focus on altering environmental values rather than conveying knowledge to promote electricity saving. If an opinion leader can be identified in the household, who decides on household investments in electrical 
equipment and drives intra-household value formation, interventions could approach this person as the primary contact.

In comparison, our models show that individual electricity consumption is only influenced by employment status and habit. Persons who stay at home during daytime (e.g. retirement, housekeeping, maternal leave, parttime jobs) and persons with a high level of automatic, non-deliberative daily actions more often undertake electricity-consuming behaviours. Thus, energy consulting interventions should primarily approach persons who stay at home. Introducing energy feedback with smart metering devices could help to break up habits by visualizing the impacts of everyday activities in real time on an in-home display. Until now, smart metering has been successfully applied in numerous countries (for reviews on different types of feedback, including smart metering, see Abrahamse et al. 2005; Fischer, 2007, 2008).

While household income is not directly related to household electricity consumption, the analyses reveal a potential indirect effect via the number of 'luxury' appliances (e.g. sauna, swimming pool) or household appliances. Instead of influencing daily electricity- consuming routines, the income level could drive appliance purchases, setting a household's base electricity load. Hence, high-income households could be targeted and informed about the electricity consumption of large appliances, either by means of efficiency labels for new appliances, or by offering engineering services for maintenance, retrofitting or optimization in device control.

Finally, our results point to the inconsistency of different individual behaviours related to electricity consumption. A detailed perspective on single behaviours could be valuable when promoting options for energy saving to specific target groups. Future research could elaborate on the motivational structure of different individual behaviours and combine such insights with weighting single actions (e.g. according to their environmental significance in carbon emissions) to use this information for educational purposes.

Acknowledgments Open access funding provided by University of Graz. This work was funded by the Austrian Climate and Energy Fund and was conducted in the program 'New Energies 2020. Grateful thanks go to two anonymous reviewers for valuable comments.

\section{Appendix}

Table 4 Quiz questions on electricity saving

\begin{tabular}{|c|c|c|c|}
\hline Item & Answers & $\begin{array}{l}\text { Percentage of } \\
\text { right answers } \\
\%\end{array}$ & $N$ \\
\hline $\begin{array}{l}\text { Which of the following activities reduces } \\
\text { stand-by electricity consumption? }\end{array}$ & $\begin{array}{l}\text { Using switchable multiple sockets for } \\
\text { turning off appliances } \\
\text { Switching off appliances with remote } \\
\text { control } \\
\text { Switching off laptops that are still } \\
\text { connected to power adaptor } \\
\text { Avoiding to frequently switch on and off } \\
\text { appliances }\end{array}$ & $95.5 \%$ & 133 \\
\hline $\begin{array}{l}\text { Which of the following activities reduces } \\
\text { energy consumption for heating (in } \\
\text { conventional houses that are not passive } \\
\text { houses)? }\end{array}$ & $\begin{array}{l}\text { Constantly airing the rooms (leaving a slit } \\
\text { of the windows constantly open) } \\
\text { Having equal temperatures in all rooms } \\
\text { Leaving the room temperature as } \\
\text { constant as possible during the heating } \\
\text { season } \\
\text { Airing and cross ventilation (open the } \\
\text { window completely for a short time) }\end{array}$ & $90.3 \%$ & 134 \\
\hline $\begin{array}{l}\text { Which of the following activities reduces } \\
\text { energy consumption when washing the } \\
\text { dishes? }\end{array}$ & $\begin{array}{l}\text { Using the dish washer } \\
\text { Manually washing the dishes } \\
\text { Washing the dishes with purified rain } \\
\text { water }\end{array}$ & $80.5 \%$ & 133 \\
\hline
\end{tabular}


Table 4 (continued)

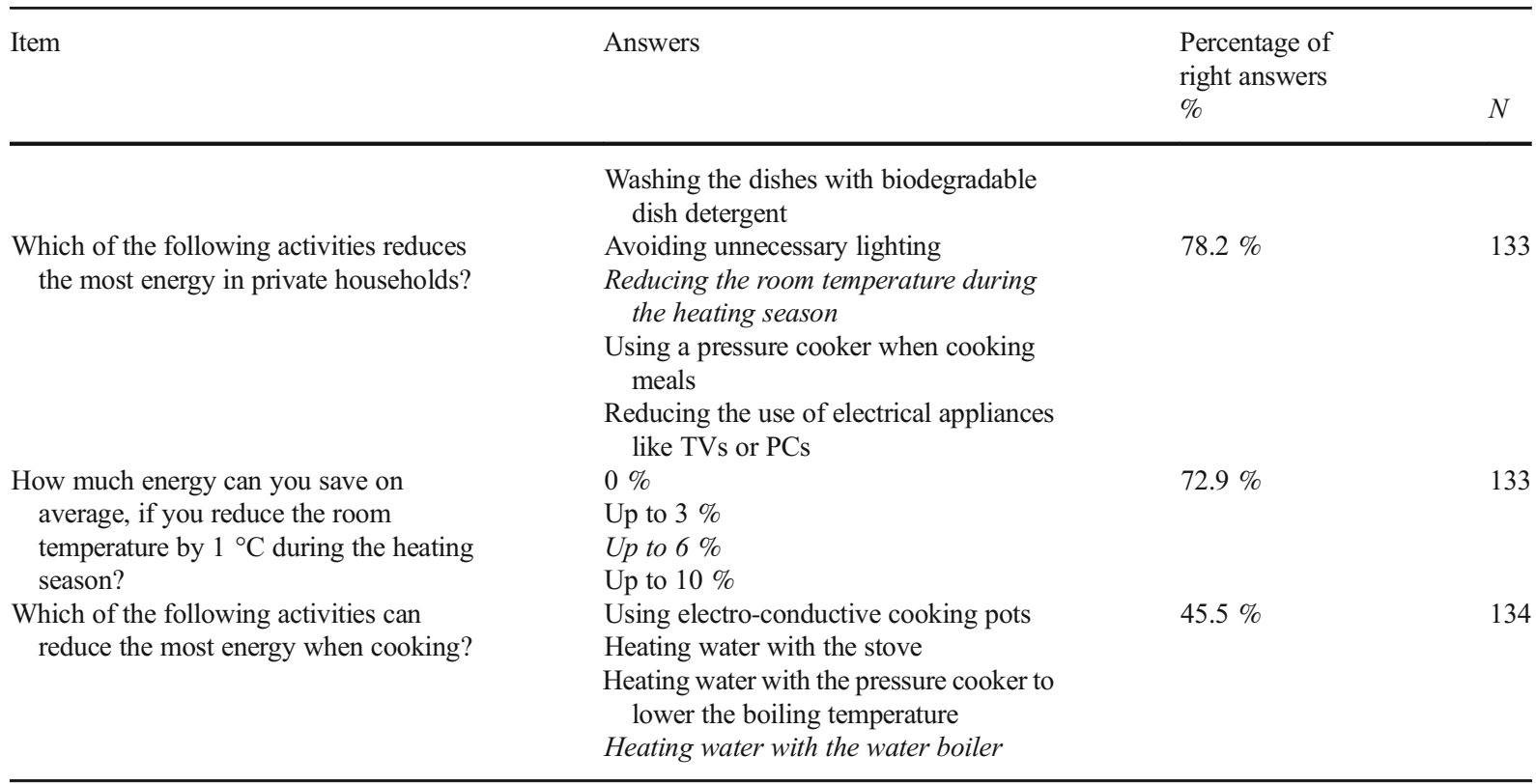

Correct answer is printed italics. The questions and answers are translated from German

Table 5 Descriptive item statistics

\begin{tabular}{|c|c|c|c|}
\hline Continuous variables & Number & Mean & SD \\
\hline Age (in years) & 195 & 51.58 & 13.38 \\
\hline Household size (in persons) & 204 & 3.12 & 1.43 \\
\hline Equivalent household income (monthly, in euro) & 164 & 1579.90 & 724.83 \\
\hline Floor area $\left(\right.$ in $\left.\mathrm{m}^{2}\right)$ & 189 & 141.96 & 67.11 \\
\hline Knowledge (sum score) & 136 & 4.12 & 1.05 \\
\hline PBC 1 & 170 & 3.28 & 1.41 \\
\hline PBC 2 & 170 & 2.39 & 1.46 \\
\hline NEP 1 & 179 & 3.43 & 0.82 \\
\hline NEP 2 & 179 & 3.42 & 0.85 \\
\hline NEP 3 & 176 & 2.62 & 1.11 \\
\hline Habit 1 & 178 & 3.27 & 1.55 \\
\hline Habit 2 & 173 & 3.47 & 1.59 \\
\hline Annual household electricity consumption in $\mathrm{kWh}$ & 189 & 4992.66 & 3266.76 \\
\hline Number of household appliances & 152 & 9.36 & 2.43 \\
\hline Number of consumer electronics & 152 & 5.85 & 2.85 \\
\hline Number of luxury appliances & 150 & 0.75 & 0.99 \\
\hline Individual electricity consumption (mean index) & 184 & 2.09 & 0.59 \\
\hline Dummy variables & $\mathrm{N}$ & Category & $\%$ \\
\hline Education & 183 & higher education $=1$ & 45.9 \\
\hline Employment & 199 & employed =1 & 57.8 \\
\hline Type of dwelling & 189 & detached house $=1$ & 66.7 \\
\hline Gender & 204 & male $=1$ & 73.0 \\
\hline
\end{tabular}


Table 6 Multiple imputation statistics on household electricity consumption

\begin{tabular}{|c|c|c|c|c|c|c|c|c|c|c|c|c|}
\hline & \multicolumn{4}{|c|}{ Listwise deletion } & \multicolumn{4}{|c|}{$\begin{array}{l}\text { Multiple imputation: } \\
\text { minimum coefficients }\end{array}$} & \multicolumn{4}{|c|}{$\begin{array}{l}\text { Multiple imputation: } \\
\text { maximum coefficients }\end{array}$} \\
\hline & $1 \mathrm{a}$ & $2 \mathrm{a}$ & $3 a$ & $4 a$ & $1 \mathrm{a}$ & $2 \mathrm{a}$ & $3 a$ & $4 a$ & $1 \mathrm{a}$ & $2 \mathrm{a}$ & $3 a$ & $4 a$ \\
\hline Household size & $.20^{* *}$ & .16 & $.17 *$ & $.19^{* *}$ & .14 & .14 & .14 & .15 & .27 & .31 & .30 & .31 \\
\hline Equivalent household income & -.02 & -.13 & -.12 & -.10 & -.08 & -.18 & -.17 & -.17 & .05 & .00 & .01 & .02 \\
\hline Type of dwelling & $.40 * *$ & $.39 * *$ & $.39 * *$ & $.37 * *$ & .20 & .20 & .21 & .21 & .27 & .29 & .30 & .30 \\
\hline Floor area & -.01 & .05 & .05 & .05 & .15 & .15 & .15 & .15 & .29 & .30 & .30 & .30 \\
\hline $\begin{array}{l}\text { Number of household } \\
\text { appliances }\end{array}$ & .11 & $.20 *$ & .19 & .15 & -.02 & .04 & .02 & .01 & .19 & .31 & .29 & .29 \\
\hline Number of consumer electronics & .16 & .13 & .09 & .11 & -.01 & -.02 & -.04 & -.05 & .17 & .16 & .15 & .14 \\
\hline Number of luxury appliances & .14 & .10 & .10 & .10 & .11 & .08 & .07 & .06 & .24 & .22 & .22 & .23 \\
\hline Gender & & .01 & .03 & .05 & & .00 & .01 & .01 & & .10 & .11 & .12 \\
\hline Age & & .11 & .08 & .06 & & -.01 & -.01 & -.01 & & .12 & .12 & .11 \\
\hline Education & & $.18^{*}$ & $.21^{* *}$ & $.21 * *$ & & .09 & .09 & .09 & & .20 & .20 & .20 \\
\hline Employment & & .01 & -.02 & -.05 & & -.11 & -.11 & -.12 & & .01 & .01 & .01 \\
\hline PBC & & .03 & .01 & .04 & & -.06 & -.07 & -.06 & & .06 & .04 & .06 \\
\hline Knowledge & & $.21 * *$ & $.19^{* *}$ & $.19^{* *}$ & & .09 & .08 & .08 & & .29 & .28 & .30 \\
\hline Environmental values & & & $-.22 * *$ & $-.24 * *$ & & & -.21 & -.20 & & & -.08 & -.07 \\
\hline Habit & & & & $-.18 * *$ & & & & -.15 & & & & .00 \\
\hline$R^{2}$ adjusted [\%] & 36.3 & 39.9 & 44.5 & 47.2 & 34.2 & 38.8 & 40.1 & 41.2 & 44.3 & 48.9 & 50.6 & 50.7 \\
\hline$R^{2}$ change $[\%]$ & - & 3.3 & 4.6 & 2.7 & - & 4.6 & 1.3 & 1.1 & 6.4 & 4.6 & 1.7 & 0.1 \\
\hline $\mathrm{F}$ & $8.6^{* * *}$ & $5.7 * *$ & $6.3 * *$ & $6.6^{* *}$ & $16.1 * *$ & $10.9 * *$ & $10.7 * *$ & $10.5 * *$ & $24.1 * *$ & $15.9 * *$ & $15.8 * *$ & $14.9 * *$ \\
\hline df & $7 / 86$ & $13 / 80$ & $14 / 79$ & $15 / 78$ & $7 / 196$ & $13 / 190$ & $14 / 189$ & $15 / 188$ & $7 / 196$ & $13 / 190$ & 14 / 189 & $15 / 188$ \\
\hline
\end{tabular}

$\mathrm{a}=$ household electricity consumption; standardized regression coefficients

$* * p<.05 ; * p<.1$

Table 7 Multiple imputation statistics on individual electricity consumption

\begin{tabular}{|c|c|c|c|c|c|c|c|c|c|c|c|c|}
\hline & \multicolumn{4}{|c|}{ Listwise deletion } & \multicolumn{4}{|c|}{$\begin{array}{l}\text { Multiple imputation: } \\
\text { minimum coefficients }\end{array}$} & \multicolumn{4}{|c|}{$\begin{array}{l}\text { Multiple imputation: } \\
\text { maximum coefficients }\end{array}$} \\
\hline & $1 b$ & $2 b$ & $3 b$ & $4 b$ & $1 b$ & $2 b$ & $3 b$ & $4 b$ & $1 b$ & $2 b$ & $3 b$ & $4 b$ \\
\hline Household size & & & & .06 & & & & -.10 & & & & .08 \\
\hline Equivalent household income & & & & .14 & & & & .00 & & & & .18 \\
\hline Type of dwelling & & & & -.11 & & & & -.03 & & & & .07 \\
\hline Floor area & & & & -.15 & & & & -.16 & & & & -.01 \\
\hline $\begin{array}{l}\text { Number of household } \\
\text { appliances }\end{array}$ & & & & .03 & & & & -.11 & & & & .22 \\
\hline $\begin{array}{l}\text { Number of consumer } \\
\text { electronics }\end{array}$ & & & & -.04 & & & & -.13 & & & & .12 \\
\hline Number of luxury appliances & & & & $-.18 *$ & & & & -.21 & & & & -.04 \\
\hline Gender & & & -.03 & -.04 & & & -.08 & -.09 & & & .02 & .02 \\
\hline Age & & & -.17 & -.12 & & & -.14 & -.13 & & & .02 & .04 \\
\hline
\end{tabular}


Table 7 (continued)

\begin{tabular}{|c|c|c|c|c|c|c|c|c|c|c|c|c|}
\hline \multirow[b]{2}{*}{ Education } & \multicolumn{4}{|c|}{ Listwise deletion } & \multicolumn{4}{|c|}{$\begin{array}{l}\text { Multiple imputation: } \\
\text { minimum coefficients }\end{array}$} & \multicolumn{4}{|c|}{$\begin{array}{l}\text { Multiple imputation: } \\
\text { maximum coefficients }\end{array}$} \\
\hline & & & .14 & .15 & & & .00 & -.02 & & & .13 & .14 \\
\hline Employment & & & $-.35 * *$ & $-.35 * *$ & & & -.33 & -.34 & & & -.18 & -.20 \\
\hline $\mathrm{PBC}$ & & & .06 & .07 & & & -.13 & -.14 & & & -.05 & -.03 \\
\hline Knowledge & & & -.04 & -.12 & & & -.09 & -.15 & & & .12 & .12 \\
\hline Environmental values & & $-.13 *$ & -.16 & $-.18 *$ & & -.16 & -.15 & -.15 & & -.02 & -.01 & -.01 \\
\hline Habit & $-.18 *$ & $-.17 *$ & $-.22 * *$ & $-.23 * *$ & -.24 & -.23 & -.22 & -.22 & -.14 & -.14 & -.12 & -.13 \\
\hline$R^{2}$ adjusted [\%] & 2.2 & 2.8 & 7.0 & 9.4 & 1.6 & 1.8 & 4.5 & 3.2 & 5.2 & 5.5 & 11.2 & 11.7 \\
\hline $\mathrm{R}^{2}$ change $[\%]$ & - & 0.6 & 4.2 & 0.0 & - & 0.2 & 2.7 & -1.3 & - & 0.3 & 5.7 & -0.2 \\
\hline $\mathrm{F}$ & $3.2 *$ & $2.4^{*}$ & $1.9^{*}$ & $1.7 *$ & $4.3 * *$ & $2.8^{*}$ & $2.2 * *$ & 1.4 & $12.1 * *$ & $6.9 * *$ & $4.2 * *$ & $2.8 * *$ \\
\hline df & $1 / 97$ & $2 / 96$ & $8 / 90$ & $15 / 83$ & $1 / 202$ & $2 / 201$ & $8 / 195$ & $15 / 188$ & $1 / 202$ & $2 / 201$ & $8 / 195$ & $15 / 188$ \\
\hline
\end{tabular}

$\mathrm{b}=$ individual electricity consumption; standardized regression coefficients

$* * p<.05 ; * p<.1$

Open Access This article is distributed under the terms of the Creative Commons Attribution 4.0 International License (http:// creativecommons.org/licenses/by/4.0/), which permits unrestricted use, distribution, and reproduction in any medium, provided you give appropriate credit to the original author(s) and the source, provide a link to the Creative Commons license, and indicate if changes were made.

\section{References}

Aarts, H., Verplanken, B., \& van Knippenberg, A. (1998). Predicting behavior from actions in the past: repeated decision making or a matter of habit? Journal of Applied Social Psychology, 28(15), 1355-1 374.

Abrahamse, W., \& Steg, L. (2009). How do socio-demographic and psychological factors relate to households' direct and indirect energy use and savings? Journal of Economic Psychology, 30, 711-720.

Abrahamse, W., Steg, L., Vlek, C., \& Rothengatter, T. (2005). A review of intervention studies aimed at household energy conservation. Journal of Environmental Psychology, 25, 273-291.

Ajzen, I. (1991). The theory of planned behavior. Organizational Behavior and Human Decision Processes, 50, 179-211.

Amburgey, J. W., \& Thoman, D. B. (2012). Dimensionality of the new environmental paradigm: issues of factor structure and measurement. Environment and Behavior, 44(2), 235-256.

Armitage, C. J., \& Conner, M. (2001). Efficacy of the theory of planned behaviour: a meta-analytic review. British Journal of Social Psychology, 40, 471-499.

Bamberg, S., Ajzen, I., \& Schmidt, P. (2003). Choice of travel mode in the theory of planned behavior: the roles of past behavior, habit, and reasoned action. Basic and Applied Social Psychology, 25(3), 175-187.

Barr, S., Gilg, A. W., \& Ford, N. (2005). The household energy gap: examining the divide between habitual- and purchase-related conservation behaviours. Energy Policy, 33, 1425-1444.

Bartiaux, F. (2008). Does environmental information overcome practice compartmentalisation and change consumers' behaviours? Journal of Cleaner Production, 16, 1170-1180.

Benders, R. M. J., Kok, R., Moll, H. C., Wiersma, G., \& Noorman, K. J. (2006). New approaches for household energy conservation - in search of personal household energy budgets and energy reduction options. Energy Policy, 34, 3612-3622.

Bertoldi, P., \& Atanasiu, B. (2007). Electricity Consumption and Efficiency Trends in the Enlarged European Union. Status Report 2006. European Commission, Directorate-General Joint Research Centre, Institute for Environment and Sustainability, EUR 22753EN. http://re.jrc.ec.europa.eu/ energyefficiency/pdf/EnEff\%20Report\%202006.pdf (retrieved 24.11.2012)

Bertoldi, P., \& Atanasiu, B. (2009). Electricity Consumption and Efficiency Trends in European Union. Status Report 2009. European Commission, Joint Research Centre, Institute for Energy, EUR 24005 EN. http://www.monitoringstelle.at/ fileadmin/dam/spritspar/downloads/News/ EnEff_Report_2009_01.pdf (retrieved 23.03.2013)

Bortz, J., \& Döring, N. (2006). Forschungsmethoden und Evaluation. New York: Springer.

Carlsson-Kanyama, A., \& Lindén, A. (2007). Energy efficiency in residences - challenges for woman and men in the North. Energy Policy, 35(4), 2163-2172.

Clark, C. F., Kotchen, M. J., \& Moore, M. R. (2003). Internal and external influences on pro-environmental behavior: participation in a green electricity program. Journal of Environmental Psychology, 23, 237-246. 
Cohen, C., Lenzen, M., \& Schaeffer, R. (2005). Energy requirements of households in Brazil. Energy Policy, 33(4), 555-562.

De Vries, P., Aarts, H., \& Midden, C. J. H. (2011). Changing simple energy-related consumer behaviors: how the enactment of intentions is thwarted by acting and non-acting habits. Environment and Behavior, 43(5), 612-633.

Dunlap, R. E. (2008). The new environmental paradigm scale: from marginality to worldwide use. Journal of Environmental Education, 40(1), 3-18.

European Environment Agency (EEA) (2012). Consumption and the Environment - 2012 update. The European Environment - State and Outlook 2010. Copenhagen, http:// www.eea.europa.eu/publications/consumption-and-the-environment-2012 (retrieved 29. 06.2012)

European Values Study (2008). http://www.europeanvaluesstudy.eu (retrieved 01.04.2014).

Fischer, C. (2007). Influencing electricity consumption via consumer feedback: a review of experience. ECEEE Summer Study, Saving Energy - just do it!

Fischer, C. (2008). Feedback on household electricity consumption: a tool for saving energy? Energy Efficiency, 1(1), 79-104.

Frick, J. (2003). Environmental knowledge. Structure, relevance for attitudes, and behavioural effectiveness. [Umweltbezogenes Wissen. Struktur, Einstellungsrelevanz und Verhaltenswirksamkeit.] Unpublished doctoral dissertation, University of Zurich.

Frick, J., Kaiser, F. G., \& Wilson, M. (2004). Environmental knowledge and conservation behavior: exploring prevalence and structure in a representative sample. Personality and Individual Differences, 37, 1597-1613.

Fujii, S., \& Kitamura, R. (2003). What does a one-month free bus ticket do to habitual drivers? An experimental analysis of habit and attitude change. Transportation, 30, 81-95.

Gatersleben, B., Steg, L., \& Vlek, C. (2002). Measurement and determinants of environmentally significant consumer behavior. Environment and Behavior, 34, 335-362.

Grønhøj, A., \& Ölander, F. (2007). A gender perspective on environmentally related family consumption. Journal of Consumer Behavior, 6, 218-235.

Grønhøj, A., \& Thøgersen, J. (2009). Like father, like son? Intergenerational transmission of values, attitudes, and behaviours in the environmental domain. Journal of Environmental Psychology, 29, 414-421.

Hurrelmann, K., Grundmann, M., \& Walper, S. (2008). Handbuch Sozialisationsforschung. Beltz Psychologie Verlags Union: Weinheim.

Kaiser, F. G., Hübner, G., \& Bogner, F. (2005). Contrasting the theory of planned behavior with the value-belief-norm model in explaining conservation behavior. Journal of Applied Social Psychology, 35(10), 2150-2170.

Kang, H., \& Scott, S. (2011). Impact of different criteria for identifying intra-household interactions: a case study of household time allocation. Transportation, 38, 81-99.

Knussen, C., \& Yule, F. (2008). "I'm not in the habit of recycling": the role of habitual behavior in the disposal of household waste. Environment and Behavior, 40(5), 683-702.

Longhi, S. (2013). Individual pro-environmental behaviour in the household context. ISER Working Paper Series 2013-21, University of Essex.
Manly, C., \& Wells, R. (2014). Reporting the use of multiple imputation for missing data in higher education research. Research in Higher Education. doi:10.1007/s11162-014-9344-9.

Newton, P., \& Meyer, D. (2012). The determinants of urban resource consumption. Environment and Behavior, 44(1), $107-135$.

Piskernik, L. (2007). Energy efficiency - the influence of knowledge and attitude. Development of psychometric scales to measure energy-related knowledge and attitudes towards energy. [Energieeffizienz - die Rolle von Wissen und Einstellung. Entwicklung von psychometrischen Skalen zur Erfassung des Energiewissens und der Energieeinstellung.] Unpublished doctoral dissertation, University of Graz.

Poortinga, W., Steg, L., \& Vlek, C. (2004). Values, environmental concern, and environmental behavior: a study into household energy use. Environment and Behavior, 36(1), 2004-70-93.

Sanquist, T. F., Orr, H., Shui, B., \& Bittner, A. C. (2012). Lifestyle factors in U.S. residential electricity consumption. Energy Policy, 42, 354-364.

Sardianou, E. (2007). Estimating energy conservation patterns of Greek households. Energy Policy, 35, 3778-3791.

Schwartz (1977). Normative influences on altruism. in: L. Berkowitz (ed.), Advances in Experimental Social Psychology, Vol. 10, Academic Press, New York, 221-279.

Schweighart, M., Seebauer, S., Fleiß, J. (2014). Consistency of pro-environmental behavior of household members and the accuracy of proxy-reports. Presented at the 28th International Congress of Applied Psychology, July 8-13, 2014, Paris.

Statistics Austria (2010). Income, poverty and living conditions 2010. Results from EU-SILC 2010. [Einkommen, Armut und Lebensbedingungen 2010. Ergebnisse aus EU-SILC 2010]. Statistics Austria, Vienna.

Statistics Austria (2011). Modeling electricity consumption in private households in Austria by purpose of use. [Modellierung des Stromverbrauchs in den privaten Haushalten Österreichs nach unterschiedlichen Verwendungszwecken.] Statistics Austria on behalf of the Federal Ministry of Agriculture and Forestry, Vienna.

Statistics Austria (2013). Electricity and gas journal 2012. Electricity and gas consumption as well as energy efficiency of Austrian households. [Strom- und Gastagebuch 2012. Strom- und Gaseinsatz sowie Energieeffizienz österreichischer Haushalte.] Statistics Austria, Vienna.

Stern, P. C. (2000). Toward a coherent theory of environmentally significant behavior. Journal of Social Issues, 56(3), 407-424.

Stern, P. C., Dietz, T., Abel, T., Guagnano, G. A., \& Kalof, L. (1999). A value belief norm theory of support for social movements: the case of environmental concern. Human Ecology Review, 6(2), 81-97.

Thøgersen, J., \& Grønhøj, A. (2010). Electricity saving in households - a social cognitive approach. Energy Policy, 38, 77327743.

Thøgersen, J., \& Ölander, F. (2002). Human values and the emergence of a sustainable consumption pattern: a panel study. Journal of Economic Psychology, 23, 605-630.

Verplanken, B. (2006). Beyond frequency: habit as mental construct. British Journal of Social Psychology, 45, 639-656.

Verplanken, B., \& Orbell, S. (2003). Reflections on past behaviour: a self-report index of habit strength. Journal of Applied Social Psychology, 33, 1313-1330. 
Whitmarsh, L. (2009). Behavioural responses to climate change: asymmetry of intentions and impacts. Journal of Environmental Psychology, 29, 13-23.

Wiesmann, D., Azvedo, I. L., Ferrao, P., \& Fernandez, J. E. (2011). Residential electricity consumption in Portugal: findings from top-down and bottom-up models. Energy Policy, 29, 27722779.

Yohanis, Y. G., Mondol, J. D., Wright, A., \& Norton, B. (2008). Real-life energy use in the UK: how occupancy and dwelling characteristics affect domestic electricity use. Energy and Buildings, 40(6), 1053-1059. 